\title{
MODELLING THE DURATION OF INTEREST RATE SPELLS UNDER INFLATION TARGETING IN CANADA*
}

\author{
Ruby Shih \& David E. Giles \\ Department of Economics, University of Victoria \\ Victoria, B.C., Canada V8W 2 Y2
}

September 2006

\begin{abstract}
We use survival models to analyze the duration of the spells associated with the interest rate used by the Bank of Canada as its monetary policy instrument. Both non-parametric and parametric models are estimated, allowing for right-censoring of the data, and time-varying covariates. We find that the data are explained well by an accelerated failure time Weibull model, with the annual rate of inflation and the quarterly rate of growth in GDP as covariates. The model indicates that there is positive duration dependence in the interest rate spells, and that unemployment and exchange rate effects are insignificant.
\end{abstract}

Keywords: $\quad$ Inflation target; survival analysis; monetary policy

JEL Classifications: $\quad$ C14; C41; E42; E43

\section{Author Contact:}

David Giles, Dept. of Economics, University of Victoria, P.O. Box 1700, STN CSC, Victoria, B.C., Canada V8W 2Y2; e-mail: dgiles@uvic.ca; FAX: (250) 721-6214 


\section{Introduction}

In recent years, interest rate policy in Canada has focused on inflation targeting, with the primary objective being to keep the core domestic inflation rate within a narrow band over time. This paper models the length of time that the Canadian central bank (the Bank of Canada) leaves its interest rate instrument unchanged. Specifically, we treat the length of time that the interest rate is left unchanged as a "spell", and use standard survival/duration analysis to analyze the data.

Using both the nonparametric Kaplan-Meier product-limit estimator, and various parametric models, we estimate the survival and hazard functions for the interest rate spells, allowing for data censoring and also for time-varying covariates in the case of the parametric models. This provides information about the nature of the duration dependence of the spells, and enables us to isolate the significant determinants of the Bank's monetary policy. Our preferred parametric model is based on the Weibull distribution, and the spells are found to exhibit positive duration dependence. Real output growth and inflation play important roles in determining the duration of bank rate spells under inflation targeting, but the rate of unemployment and exchange rate considerations do not emerge as significant factors at all.

The layout of the rest of this paper is as follows. Section 2 provides background information on monetary policy and inflation targeting, with an emphasis on the Canadian situation. The econometrics of modeling duration data are summarized in section 3, and section 4 describes our data. Our main statistical results are reported in section 5, and the final section summarizes our conclusions.

\section{Monetary Policy and Inflation Targeting}

Around 1990, several countries adopted inflation targeting as the focus of their monetary policy. The objective of the policy is to deliver price stability - that is, low inflation - so as to foster economic growth and employment. The early adopters of inflation targeting were mostly industrialized countries. In chronological order they were New Zealand (1989), Canada (1991), the United Kingdom (1992), Sweden (1993), and Australia (1993). Recently, certain middleincome developing countries and transition economies have begun to adopt this framework of monetary policy as an experiment. ${ }^{1}$ Table 1 indicates the range of countries which have now adopted inflation targeting, and also shows the wide range of variations that this policy can take. 
Canada has adopted inflation targeting since $1991 .^{3}$ In February 1991, the federal government and the Bank of Canada jointly announced that they intended to reduce inflation to the midpoint of a band of 1 to 3 percent by the end of 1995. This inflation control target range was subsequently extended several times. The last extension was decided in May 2001, with a dateline to the end of 2006.

Inflation targeting in Canada is measured by the consumer's price index (CPI), which is published monthly with a very short publication delay, and no revisions. The timeliness and quality of the data used to construct the CPI render it very suitable for targeting purposes. However, in order to exclude movements in the CPI caused by fluctuations in the prices of food and energy, as well as changes associated with indirect taxes, the Bank of Canada uses the "core" CPI. This measure nets out inflationary effects from these sources, and provides a more realistic inflationary indicator. In the long run, the CPI and its core counterpart exhibit very similar trends. Thus, while the Bank acts so as to keep the core CPI within the desired range, the CPI itself also tends to be maintained within the band over time. For more details, see Macklem (2001).

The policy instrument that is used for conducting monetary policy in Canada is the overnight lending rate, which is the interest rate charged on overnight loans between financial intermediaries. The target for the overnight lending rate signals the average interest rate the Bank intends to have in the marketplace. A change in the target overnight lending rate has a very strong influence on other interest rates, including mortgage rates and the prime rate charged by commercial banks. The operating band for the overnight rate is one-half of a percentage point wide, and is centered at the target for the overnight lending rate. This defines the spread between the bank rate and the deposit rate - the top of the band is the bank rate (the rate of interest charged by the Bank on loans made to financial institutions); and the bottom of the band is the so-called deposit rate, which is the rate paid by the central bank on any net positive settlement balances held overnight. As the Bank will always lend money at the top of the band and pay interest at the bottom of the band, the institutions will never trade funds at rates outside the operating band. If for some reason the market rate is not in the desired range, the Bank can always intervene in the overnight market by adjusting the target rate. Therefore, the target overnight lending rate, or the cash rate, is an extremely expedient means of implementing adjustments to achieve an inflation target. 
The change in the overnight lending rate will have a powerful influence on other interest rates, and will indirectly adjust inflation towards the desired level. Interest rates will affect many aspects of economic activity such as savings and investment behavior, consumer spending behavior, and the exchange rate. All of these will change the level of aggregate demand and hence alter the level of inflation. For example, in order to prevent inflation from moving below the target range, the Bank of Canada can decrease the overnight lending rate, making market interest rates decrease and the dollar depreciate. The dollar will decrease in its value due to the lower interest rates in comparison with those in other countries. Investors will choose to invest relatively less in Canada, thus causing a decrease in demand for the local dollar; therefore, Canadian dollar depreciates. Both the interest rate and the exchange rate activate the increase in spending namely the increase in demand. The reduction in interest rates decreases the borrowing costs, thus increasing the demand for goods and services. The depreciation in the dollar makes imports more expensive and exports cheaper, boosting the demand for domestic importcompeting goods and for exports. Higher demands cause higher prices. As a result, this transmission mechanism achieves the goal of raising the rate of inflation.

The Canadian core inflation rate and the overnight lending rate from January, 1996 to December, 2004, are shown in Figure 1. Core inflation and the overnight lending rate have opposite trends. When core inflation falls, the Bank adjusts the overnight lending rate to keep the inflation inside the band, and vice versa.

\section{Modeling Survival Data}

Duration analysis, or survival analysis, has now found widespread application in economics. It can be useful whenever we want to estimate the likelihood that a certain event will end in the next short interval, given that it has already lasted for a period of time. Examples of the application of survival analysis in economics include studies of the length of unemployment spells (e.g., Katz, 1986, and Kiefer, 1988), and the duration of strikes (e.g., Kennan, 1985). Setzer (2004), Walti (2005) and $\mathrm{Yu}(2005)$ studied the duration of exchange rate regimes from different perspectives; and Leung et al. (2003) applied survival analysis to examine the entry of foreign banks in the People's Republic of China. Other interesting economic examples of the application of duration analysis include Li's (1999) Bayesian duration analysis of the lengths of time that firms spend in Chapter 11 bankruptcy in the U.S.A., Xie's (2006) study of the time between application and granting of patents in the U.S., and Giles' (2006) analysis of the survival of number one hits on 
the Hot 100 chart for the U.S. music industry. An excellent discussion of survival analysis from an economic perspective is provided by Lancaster (1990).

The layout of duration model analysis is as follows. The distribution function for the duration that is to be modelled is $F(t)=\operatorname{Pr}$. [ $T<t]$. Here, $T$ is a continuous, non-negative, random variable representing a period of time; $t$ is the value of this specified random variable. The density function of $F(t)$ is defined as $f(t)=d F(t) / d t$. An alternative (and equivalent) way of specifying the distribution of $\mathrm{T}$ is in terms of the survival function, defined as $S(t)=1-F(t)=\operatorname{Pr}$. $[T \geq t]$. This represents the upper tail area of the distribution. That is, it provides the probability that the length of a spell is at least ' $t$ ' periods. The hazard function, $\lambda(t)=(f(t) / S(t))=d F(t) / d t) / S(t)=$ $(-d S(t) / d t)=-d \ln S(t) / d t$, is another useful function for duration analysis. It is the instantaneous rate at which spells will be completed at duration $t$, given that they have lasted that long. Differentiating the hazard function with respect to $t$, we can identify the nature of any 'duration dependence'. If $d \lambda(\mathrm{t}) / d t>0$ at $t=t^{*}$, we say there is a positive duration dependence at time $t^{*}$. As the spell length increases at this time, the probability that the spell will end within a short period of time increases. Negative duration dependence exists at $t^{*}$ if $d \lambda(\mathrm{t}) / d t<0$ at $t=t^{*}$. The integrated hazard function, defined as $\Lambda(t)=\int_{0}^{t} \lambda(u) d u$, can be used for specification checks in subsequent parametric survival analysis. However, it is important to note that the integrated (or cumulative) hazard function is not a probability, and so its interpretation is not always straightforward. The distribution, density, survival, and hazard functions provide alternative ways of viewing the underlying random behaviour of the variable ' $T$ '.

\subsection{Nonparametric Model}

The popular survival analysis technique, the Kaplan and Meier (1958) product-limit estimator, can be used to estimate the survival and hazard functions. This nonparametric method can be a useful graphical aid for preliminary analyses such as suggesting functional forms and model specification when the underlying distribution of $T$ is unknown. In addition, it has an advantage in not depending upon the choice of intervals. In a sample of survival data, each observation is either complete or censored. Suppose there are $n$ observations on $T$, and the completed durations in this sample are assumed to be ordered as $t_{1}<t_{2}<\ldots \ldots<t_{k}$. Due to censoring issues and possible "ties" in the data, the number of completed spells, $k$, is generally less than sample size, $n$. As an example, in our dataset, $n=120$ and $k=8$. Let $h_{j}$ represent the number of completed 
spells of duration $t_{j}(j=1,2, \ldots, k)$. Let $m_{j}$ denote the number of observations censored between $t_{j}$ and $t_{j+1}$, and $m_{k}$ denotes the number of observations whose duration greater than $t_{j}$, the longest complete duration. Finally, let $n_{j}$ represents the number of spells that are not censored or not complete before duration $t_{j}$. Therefore, $n_{j}=\sum_{i \geq j}^{k}\left(m_{i}+h_{i}\right)$. Regardless of any censoring, the estimated survival and hazard functions are step functions. A natural estimator of the hazard function is $\hat{\lambda}\left(t_{j}\right)=\left(h_{j} / n_{j}\right)$. The corresponding estimator for the survival function is $\hat{s}\left(t_{j}\right)=\prod_{i=1}^{j}\left[\left(n_{i}-h_{i}\right) / n_{i}\right]=\prod_{i=1}^{j}\left(1-\hat{\lambda}_{i}\right) \cdot(j=1,2, \ldots, k)$.

\subsection{Parametric Survival Models with Time-Varying Covariates}

Another way to model duration data is by using parametric methods. As we do not know the exact functional form of the hazard function, in this study we begin with three of the most common hazard function formulations - Exponential, Weibull, and Log-logistic - and then select the most appropriate model for describing the distribution of data. The most recent observation is right-censored in our sample. That is, this last spell was yet to be completed at the time the study was undertaken. Censored data points have to be treated differently from the complete spells in the formulation of the likelihood function, and an allowance also has to be made for the fact that our explanatory variables change in value during the "life" of a spell. For example, the interest rate may be held constant for five months, but the value of the CPI will be changing from month to month in the sample. In the case of such time-varying covariates the log-likelihood function in this case is the sum of terms of the form $\log L_{i}=\delta_{i} \log h\left(t_{k} \mid x_{k}\right)-\sum_{j=1}^{k} \int_{t_{j-1}}^{t_{j}} h\left(s \mid x_{j}\right) d s$, where $\delta_{i}=1$ for complete observations; $\delta_{i}=0$ for censored observations. This complicates the estimation problem, and we have used the LIMDEP package (Greene, 2002) for the parametric modeling.

Table 2 summarizes the details of survival, hazard, and integrated hazard functions under the three parametric distributions that we are considering. Two unknown (location and shape) parameters $\theta$ and $p$ are involved in these functions, and they can be estimated by the method of maximum likelihood. We set $\theta=\exp \left(-\beta^{\prime} X_{i}\right)$, where $X_{i}$ is a vector with values of the covariates at observation $i$, and $\beta$ is the corresponding vector of coefficients. In the Weibull model, if $p>1$ ( $p$ $<1$ ), then the hazard function exhibits positive (negative) duration; when $p=1$, the Weibull model collapses to the Exponential model and the hazard function is flat (so there is no duration 
dependence). In the Log-logistic model, if $p \leq 1$, there is negative duration dependence for the hazard; and if $p>1$, the hazard function has an inverted U-shape. We will follow a general-tospecific modeling approach to get the preferred model specification. Model selection is based primarily on the statistical significance of the covariates. Akaike's information criterion (AIC) will be used to make a choice between non-nested competing models that are satisfactory in other respects.

\section{Data}

Our data are from the official website of the Bank of Canada. Monthly data were collected from January, 1996 to December, 2004 (i.e., 108 observations). The variable definitions are listed below. They include all of the variables used or constructed for the purpose of evaluating the significance of potential covariates. All data were available on a monthly basis, except for GDP. So, the latter data were interpolated, using the routines in the EViews package (Quantitative Micro Software, 2004), from quarterly to monthly. We then generated both the annual \% change in real GDP (GDPGA) and the monthly \% change in real GDP (GDPGM), to allow us to explore the possible importance of growth in output, both in the very recent past, and also over a somewhat longer time-horizon. In the case of core inflation, only the annual rate was considered, in keeping with the declared policy of the Bank of Canada. The variables in our models are:

INFCA Annual inflation rate based on the core CPI

GDPGA Annual \% change in real seasonally adjusted, GDP

GDPGM Monthly \% change in real seasonally adjusted, GDP

UE Seasonally adjusted unemployment rate

XR Exchange rate (US\$ / CDN\$)

$\mathrm{T} \quad$ Length of spell for the overnight interest rate

DELTA $\quad \delta_{i}=1$ for complete observations; $=0$ for right-censored observations

INFCA, GDPGA (or GDPGM), UE and XR are the chosen regressors which we expect may have some impact on the duration of the interest rate spell, $T$. 


\section{Results}

Figure 2 depicts the Kaplan-Meier survival function with a 95\% confidence band, the latter being based on Greenwood's (1926) formula. The survival function is downward sloping and declines at a decreasing rate, so a spell is less likely to be lengthened as time increases. Figure 3 shows the corresponding hazard and integrated hazard functions. The hazard function first decreases and then increases. There is a $57 \%$ chance that the spell will end after one month. After the first month, this probability starts to decrease until the fifth month. From five months to six months, the hazard rate increases from $16.7 \%$ to $20 \%$ indicating the likelihood of an interest rate spell ending starts to increase once the duration reaches more than five months. Of course, this nonparametric appraisal of the data ignores the role of covariates that may affect the duration of interest rate spells.

The LIMDEP econometrics package (Greene, 2003) was used to estimate our parametric models with time-varying covariates. The preferred model specification was obtained by following a general-to-specific modeling strategy. The preferred results for each parametric model are summarized in Tables 3 to 5. Table 3 reports results using the annual growth rate of GDP instead of the monthly growth rate (as in Table 4), but the monthly rate is preferred on the basis of the significance of the covariates. As we cannot reject the hypothesis that $p=1$ for either of the Weibull models in Table 4, this lends some support for the Exponential models. However, this has to be weighed against the insignificance of the regressors in the latter models. Table 5 shows the results for the six most representative Weibull models, and we conclude that model 4 is the preferred model, again because of the significance of its covariates. The annual rate of inflation and the monthly growth rate of real GDP have a significant influence on the duration of interest rate spells, and the Weibull distribution is the most appropriate underlying distribution. The implied median duration for an interest rate spell is estimated to be 1.7 months, which compares well with the sample median of two months. ${ }^{5}$

Figures 4 to 6 depict the survival, hazard and cumulative hazard functions for the preferred Weibull model. The survival function roughly corresponds to the Kaplan and Meier downward sloping survival function. In contrast to the Kaplan-Meier results, and as might be anticipated, the estimated hazard function for the Weibull distribution is monotonically increasing showing that there is positive duration dependence. In other words, the likelihood of a spell ending in the next period always increases as time passes. For example, after one month the probability of the 
interest rate being changed in the next period is $44 \%$, while it is just over $70 \%$ when the rate has been held constant for five months. Finally, the cumulative hazard function is approximately an upward sloping straight line, which is usually interpreted as signaling the correctness of the chosen functional form.

The marginal effects for the core inflation rate and the monthly rate of growth in GDP can be obtained by using the result that, in the notation of section 3, for the Weibull model $E\left(T \mid X_{i}\right)=\exp \left(\beta^{\prime} X_{i}\right) \Gamma[(1 / p)+1]=\Gamma[(1 / p)+1] / \theta$. So, the marginal effect for the $j^{\prime}$ th regressor is $\partial\left[E\left(T \mid X_{i}\right)\right] / \partial x_{i j}=\beta_{j} \Gamma[(1 / p)+1] / \theta$, where $x_{i j}$ is the $i$ th observation on the $j$ th regressor. ${ }^{6}$ For the preferred model 4, using the sample means of the data, the marginal effects for the inflation rate and GDP growth are 0.647 and 2.262 respectively. So, a change in the annual core inflation rate of one percentage point implies a 0.65 month change in the expected duration of an interest rate spell. This is a substantial increase in core inflation, as the average rate for our sample is $1.8 \%$ p.a. The average monthly growth rate in real GDP in the sample is $0.27 \%$. If this growth rate were doubled, our model predicts that the Bank of Canada would be expected to increase the interest rate spells by $(0.27 \times 2.262)=0.61$ months.

\section{Conclusions}

In this paper we have studied the duration of bank rate spells under inflation targeting in Canada. We found that the Weibull model with the annual rate of core inflation and monthly growth rate of real GDP as independent variables provides a good description of the survival function and the hazard function. The estimated hazard function for the Weibull distribution is monotonically increasing, implying positive duration dependence for the interest rate spells. Interestingly, the unemployment rate and the U.S./Canada exchange rate are insignificant as determinants of the interest rate spells. In fact, the international empirical evidence relating to the importance of nominal exchange rate changes for interest rate policy under inflation targeting is very mixed. With respect to Canada, Gerlach and Smets (2000) found a significant relationship, whereas Hüfner (2004) found the opposite when a longer sample period was considered. ${ }^{7}$ Our results provide some support for the notion that the way in which the Bank of Canada implements its monetary policy is described quite well by a rudimentary "Taylor rule". This stands in contrast to Dib's (2006) recent finding that money growth is also an important factor - a finding that could be explored further in a duration analysis setting. 
Table 1: Inflation Targeting in Various Countries

\begin{tabular}{|c|c|c|}
\hline Country & $\begin{array}{c}\text { Target } \\
(\%)\end{array}$ & Further details \\
\hline Australia & $2-3$ & On average over the business cycle \\
\hline \multirow[t]{2}{*}{ Brazil } & 4.5 & In 2005 ; tolerance band of $+/-2.5$ percentage points \\
\hline & 4.5 & In 2006; tolerance band of $+/-2$ percentage points \\
\hline Canada & $1-3$ & Through to the end of $2006 ; 6-8$ quarter horizon \\
\hline Chile & $2-4$ & Over the medium term, i.e. 12 to 24 months \\
\hline \multirow[t]{2}{*}{ Colombia } & $4.5-5.5$ & In 2005 \\
\hline & $2-4$ & In the long term \\
\hline \multirow[t]{2}{*}{ Czech Republic } & $2-4$ & By December 2005 \\
\hline & 3 & $\begin{array}{l}\text { Thereafter until accession to the euro area; tolerance band of }+/-1 \\
\text { percentage point }\end{array}$ \\
\hline Euro Area & $<2$ & $\begin{array}{l}\text { Below but close to } 2 \text { per cent; over the medium term; for the euro } \\
\text { area as a whole }\end{array}$ \\
\hline \multirow[t]{2}{*}{ Hungary } & 4 & By December 2005; tolerance band of $+/-1$ percentage point \\
\hline & 3.5 & By December 2006; tolerance band of $+/-1$ percentage point \\
\hline Iceland & 2.5 & Tolerance band of $+/-1.5$ percentage points \\
\hline Israel & $1-3$ & \\
\hline Mexico & 3 & Tolerance band of $+/-1$ percentage point \\
\hline New Zealand & $1-3$ & On average over the medium term \\
\hline Norway & 2.5 & Over the medium term, usually 1 to 3 years \\
\hline Peru & 2.5 & Tolerance band of $+/-1$ percentage point \\
\hline \multirow[t]{2}{*}{ Philippines } & $5-6$ & In 2005 \\
\hline & $4-5$ & In 2006 \\
\hline Poland & 2.5 & Tolerance band of $+/-1$ percentage point \\
\hline South Africa & $3-6$ & Headline inflation excluding mortgage interest cost \\
\hline South Korea & $2.5-3.5$ & Core inflation; annualized average during 2004-2006 \\
\hline Sweden & 2 & 1-2 year horizon; tolerance band of $+/-1$ percentage point \\
\hline Switzerland & $<2$ & \\
\hline Thailand & $0-3.5$ & Quarterly average of core (annual) inflation \\
\hline United Kingdom & 2 & Tolerance band of $+/-1$ percentage point \\
\hline
\end{tabular}

Source: Reserve Bank of Australia, http://www.rba.gov.au 
Table 2: Parametric Density, Survival and Hazard Functions

Log-logistic
Weibull

$\theta p(\theta t)^{p-1} \exp \left[-(\theta t)^{p}\right]$

$\exp \left[-(\theta t)^{p}\right]$

$\theta p(\theta t)^{p-1}$

$(\theta t)^{p}$

Note: \begin{tabular}{ll}
$\mathbf{S}(\mathbf{t})$ & $1 /\left[1+(\theta t)^{p}\right]$ \\
$\boldsymbol{\lambda}(\mathbf{t})$ & $\theta p(\theta t)^{p-1} /[1+$ \\
$\mathbf{\Lambda ( t )}$ & $\log \left[1+(\theta t)^{p}\right]$ \\
\hline
\end{tabular}

$\theta p(\theta t)^{p-1} /\left[1+(\theta t)^{p}\right]^{2}$

\begin{tabular}{ll}
$\mathbf{S}(\mathbf{t})$ & $1 /\left[1+(\theta t)^{p}\right]$ \\
$\boldsymbol{\lambda}(\mathbf{t})$ & $\theta p(\theta t)^{p-1} /[1$ \\
$\mathbf{\Lambda ( t )}$ & $\log \left[1+(\theta t)^{p}\right]$ \\
\hline
\end{tabular}

\begin{tabular}{ll}
$\mathbf{S ( t )}$ & $1 /\left[1+(\theta t)^{p}\right]$ \\
$\boldsymbol{\lambda}(\mathbf{t})$ & $\theta p(\theta t)^{p-1} /\left[1+(\theta t)^{p}\right]$ \\
$\mathbf{\Lambda ( t )}$ & $\log \left[1+(\theta t)^{p}\right]$ \\
\hline
\end{tabular}

\section{Exponential}

$\theta \exp (-\theta t)$

$\exp (-\theta t)$

$\theta$

$\theta t$

\author{
distribution when $p=1$.
}


Table 3: Maximum Likelihood Estimation of Parametric Models

(Annual Growth Rates)

\begin{tabular}{|c|c|c|c|c|c|c|}
\hline & \multicolumn{2}{|c|}{ Exponential } & \multicolumn{2}{|c|}{ Weibull } & \multicolumn{2}{|c|}{ Log-Logistic } \\
\hline \multirow[t]{2}{*}{ Intercept } & 1.1264 & & 0.8876 & & 2.7276 & \\
\hline & $(4.7459)$ & & $(2.9930)$ & & $(2.2800)$ & \\
\hline \multirow[t]{2}{*}{ INFCA } & 0.0160 & 0.4044 & 0.0424 & 0.4421 & -0.0257 & 0.1980 \\
\hline & $(0.4177)$ & $(0.0954)$ & $(0.2235)$ & $(0.0886)$ & $(0.2348)$ & $(0.0679)$ \\
\hline \multirow[t]{2}{*}{ GDPGA } & 0.3068 & & 0.3508 & & 0.1618 & \\
\hline & $(0.2382)$ & & $(0.1426)$ & & $(0.1241)$ & \\
\hline \multirow[t]{2}{*}{$\mathbf{U E}$} & -0.1159 & & -0.1183 & & -0.1561 & \\
\hline & $(0.2308)$ & & $(0.1354)$ & & $(0.1153)$ & \\
\hline \multirow[t]{2}{*}{ XR } & -0.2669 & & -0.1360 & & -0.9968 & \\
\hline & $(2.4361)$ & & $(1.5411)$ & & $(1.2112)$ & \\
\hline \multirow[t]{2}{*}{$\theta$} & 0.4802 & 0.4767 & 0.4308 & 0.4448 & 0.6390 & 0.6958 \\
\hline & $(0.1039)$ & $(0.0833)$ & $(0.0619)$ & $(0.0722)$ & $(0.0787)$ & $(0.0866)$ \\
\hline \multirow[t]{2}{*}{$p$} & 1.0000 & 1.0000 & 1.5343 & 1.2253 & 2.8571 & 2.5336 \\
\hline & $(0.0000)$ & $(0.0000)$ & $(0.2660)$ & $(0.1878)$ & $(0.4654)$ & $(0.4285)$ \\
\hline \multirow[t]{2}{*}{ Median } & 1.4436 & 1.4542 & 1.8282 & 1.6669 & 1.5650 & 1.4373 \\
\hline & $(0.3125)$ & $(0.2542)$ & $(0.2627)$ & $(0.2705)$ & $(0.1928)$ & $(0.1788)$ \\
\hline AIC & 199.700 & 209.698 & 190.690 & 207.484 & 171.814 & 185.043 \\
\hline
\end{tabular}

Note: Asymptotic standard errors appear in parentheses.

'Median' is the estimated median survival time.

'Median' and ' $\theta$ '" are calculated using the sample means of the data. 
Table 4: Maximum Likelihood Estimation of Parametric Models

(Monthly Growth Rates)

\begin{tabular}{|c|c|c|c|c|c|c|}
\hline & \multicolumn{2}{|c|}{ Exponential } & \multicolumn{2}{|c|}{ Weibull } & \multicolumn{2}{|c|}{ Log-logistic } \\
\hline \multirow[t]{2}{*}{ Intercept } & 3.4734 & & 3.3185 & & 4.3703 & \\
\hline & $(4.3257)$ & & $(3.0332)$ & & $(2.1381)$ & \\
\hline \multirow[t]{2}{*}{ INFCA } & -0.0310 & 0.2690 & 0.0154 & 0.3090 & -0.1269 & 0.1309 \\
\hline & $(0.4003)$ & $(0.1380)$ & $(0.2403)$ & $(0.1113)$ & $(0.2335)$ & $(0.0934)$ \\
\hline \multirow[t]{2}{*}{ GDPGM } & 0.6982 & 1.0408 & 0.7215 & 1.0800 & 0.3779 & 0.6402 \\
\hline & $(0.9173)$ & $(0.7635)$ & $(0.5936)$ & $(0.5414)$ & $(0.4580)$ & $(0.4477)$ \\
\hline \multirow[t]{2}{*}{$\mathbf{U E}$} & -0.2203 & & -0.2284 & & -0.2200 & \\
\hline & $(0.2161)$ & & $(0.1434)$ & & $(0.1170)$ & \\
\hline \multirow[t]{2}{*}{ XR } & -0.7047 & & -0.5433 & & -1.3744 & \\
\hline & $(2.3689)$ & & $(1.6444)$ & & $(1.1778)$ & \\
\hline \multirow[t]{2}{*}{$\theta$} & 0.4711 & 0.4793 & 0.4261 & 0.4413 & 0.6427 & 0.6777 \\
\hline & $(0.0925)$ & $(0.0857)$ & $(0.0673)$ & $(0.0661)$ & $(0.0751)$ & $(0.0794)$ \\
\hline \multirow[t]{2}{*}{$p$} & 1.0000 & 1.0000 & 1.4127 & 1.2960 & 2.8489 & 2.5740 \\
\hline & $(0.0000)$ & $(0.0000)$ & $(0.2459)$ & $(0.1801)$ & $(0.4748)$ & $(0.4294)$ \\
\hline \multirow[t]{2}{*}{ Median } & 1.4714 & 1.4462 & 1.8106 & 1.7079 & 1.5558 & 1.4757 \\
\hline & $(0.2888)$ & $(0.2586)$ & $(0.2862)$ & $(0.2556)$ & $(0.1819)$ & $(0.1729)$ \\
\hline AIC & 201.767 & 206.054 & 192.956 & 201.434 & 172.975 & 182.316 \\
\hline
\end{tabular}

Note: $\quad$ Asymptotic standard errors appear in parentheses.

'Median' is the estimated median survival time.

'Median' and ' $\theta$ ' are calculated using the sample means of the data 
Table 5: Maximum Likelihood Estimation of Weibull Models (Monthly Growth Rates)

\begin{tabular}{|c|c|c|c|c|c|c|}
\hline Model: & 1 & 2 & 3 & 4 & 5 & 6 \\
\hline \multirow[t]{3}{*}{ INFCA } & 0.0045 & 0.1420 & -0.0708 & 0.3090 & & \\
\hline & $(0.2510)$ & $(0.2543)$ & $(0.2397)$ & $(0.1113)$ & & \\
\hline & {$[0.9856]$} & {$[0.5765]$} & {$[0.7678]$} & {$[0.0055]$} & & \\
\hline \multirow[t]{3}{*}{ GDPGM } & 0.7754 & 0.9792 & 0.7808 & 1.0800 & 0.9761 & 0.7922 \\
\hline & $(0.5658)$ & $(0.5886)$ & $(0.5769)$ & $(0.5414)$ & $(0.5986)$ & $(0.5702)$ \\
\hline & {$[0.1706]$} & {$[0.0962]$} & [0.1759] & {$[0.0461]$} & {$[0.1030]$} & [0.1647] \\
\hline \multirow[t]{3}{*}{$\mathbf{U E}$} & -0.1177 & 0.0424 & & & 0.0737 & \\
\hline & $(0.0975)$ & $(0.0628)$ & & & $(0.0287)$ & \\
\hline & {$[0.2275]$} & {$[0.5002]$} & & & {$[0.0102]$} & \\
\hline \multirow[t]{3}{*}{ XR } & 1.1362 & & 0.5623 & & & 0.4713 \\
\hline & $(0.5485)$ & & $(0.3314)$ & & & $(0.1598)$ \\
\hline & [0.0383] & & [0.0897] & & & {$[0.0032]$} \\
\hline \multirow[t]{2}{*}{$\theta$} & 0.4286 & 0.4327 & 0.4239 & 0.4413 & 0.4337 & 0.4231 \\
\hline & $(0.0674)$ & $(0.0697)$ & $(0.0691)$ & $(0.0661)$ & $(0.0707)$ & $(0.0685)$ \\
\hline \multirow[t]{2}{*}{$p$} & 1.3963 & 1.3113 & 1.3611 & 1.2960 & 1.3002 & 1.3625 \\
\hline & $(0.2526)$ & $(0.2097)$ & $(0.2550)$ & $(0.1801)$ & $(0.2095)$ & $(0.2543)$ \\
\hline \multirow[t]{2}{*}{ Median } & 1.7944 & 1.7477 & 1.8023 & 1.7079 & 1.7395 & 1.8060 \\
\hline & $(0.2821)$ & $(0.2817)$ & $(0.2938)$ & $(0.2556)$ & $(0.2835)$ & $(0.2923)$ \\
\hline AIC & 194.9396 & 200.6393 & 197.1577 & 201.4336 & 201.1638 & 197.292 \\
\hline
\end{tabular}

Note:

Asymptotic standard errors appear in parentheses, with p-values in square brackets.

'Median' is the estimated median survival time. 'Median' and ' $\theta$ ' are calculated using the sample means of the data. 
Figure 1: Canadian Core Inflation \& Overnight Lending Rate

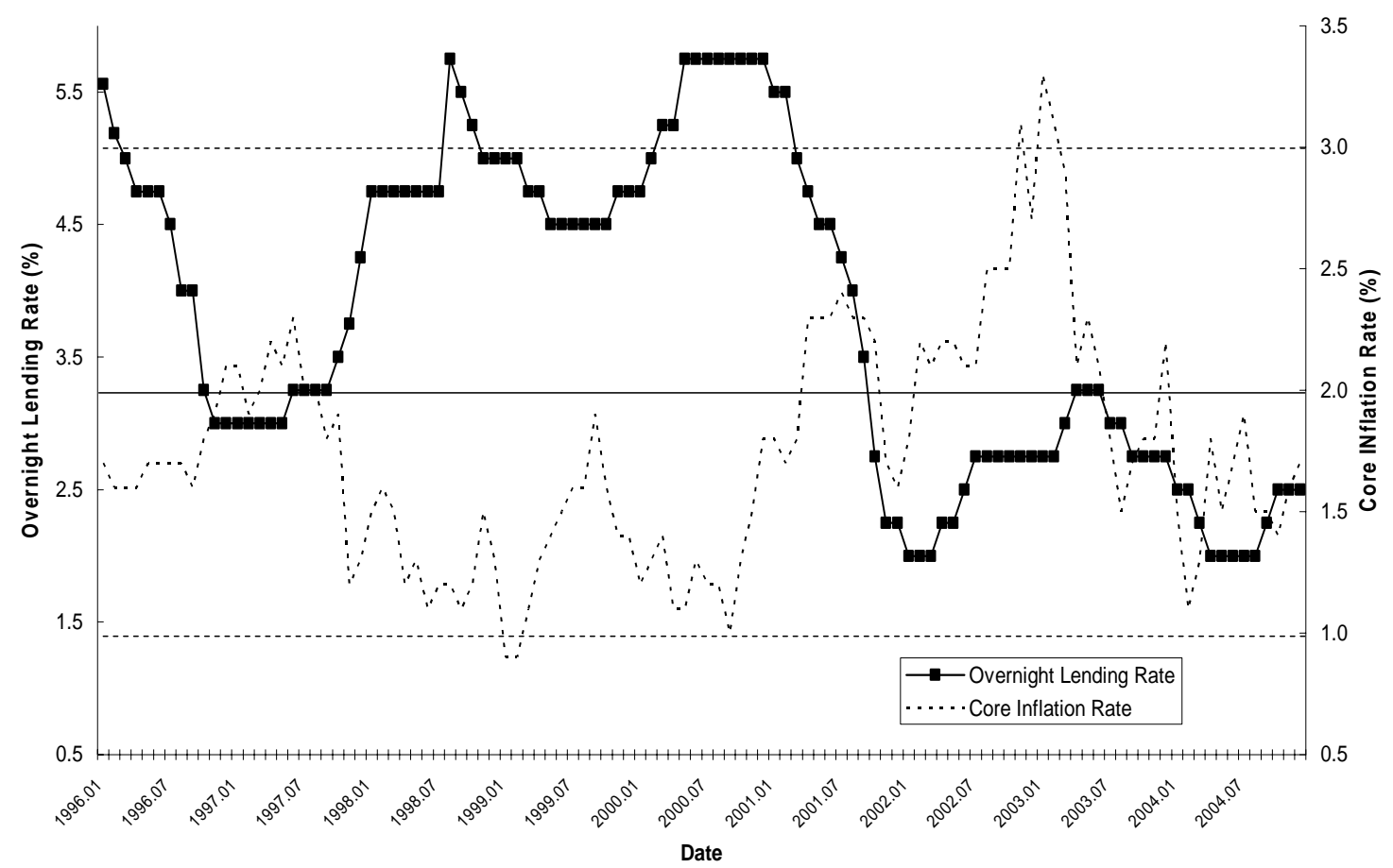

Figure 2: Kaplan-Meier Survival Function (With 95\% Confidence Band)

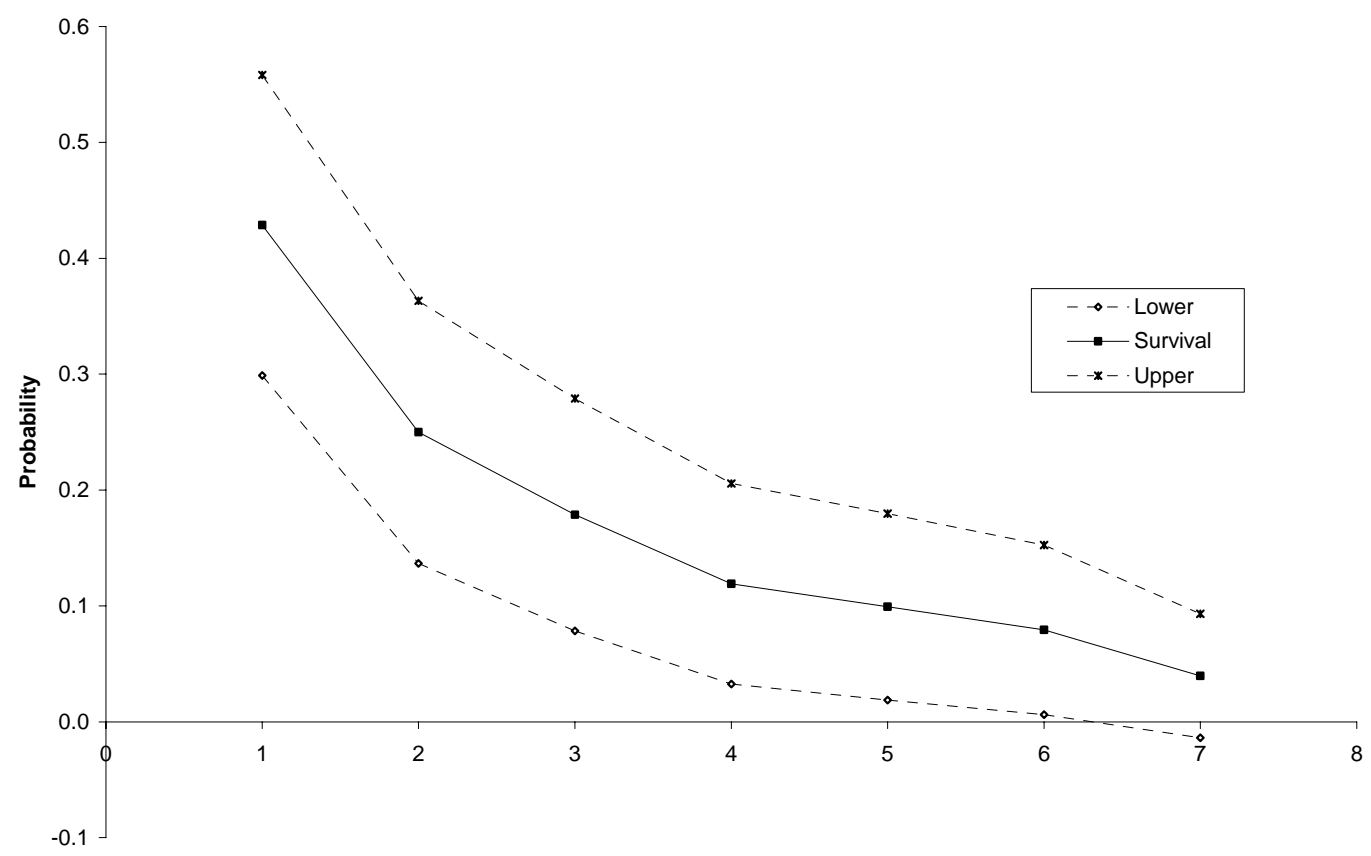

Spell Length (Months) 
Figure 3: Kaplan-Meier Hazard \&

Cumulative Hazard Functions

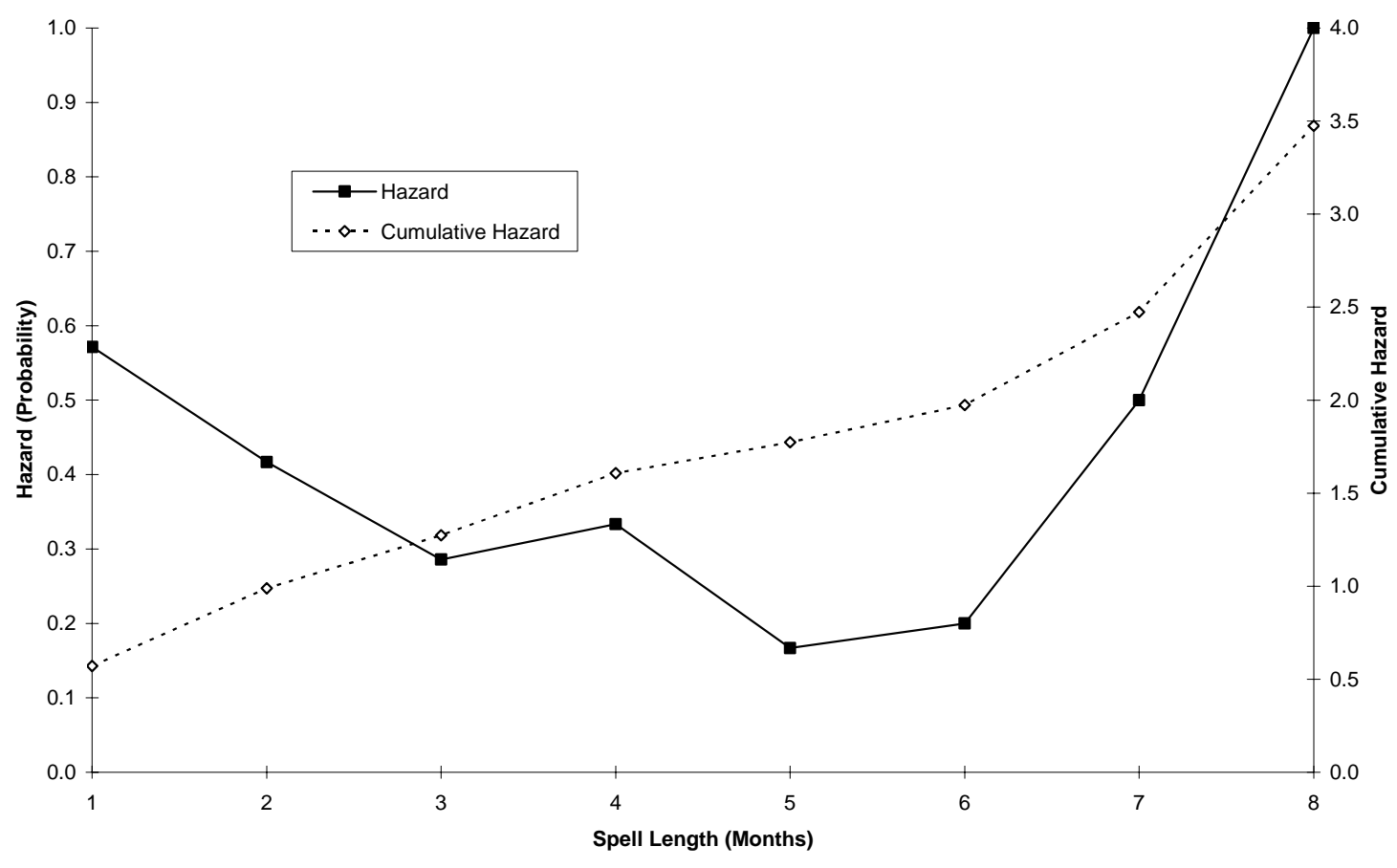

Figure 4: Weibull Survival Function

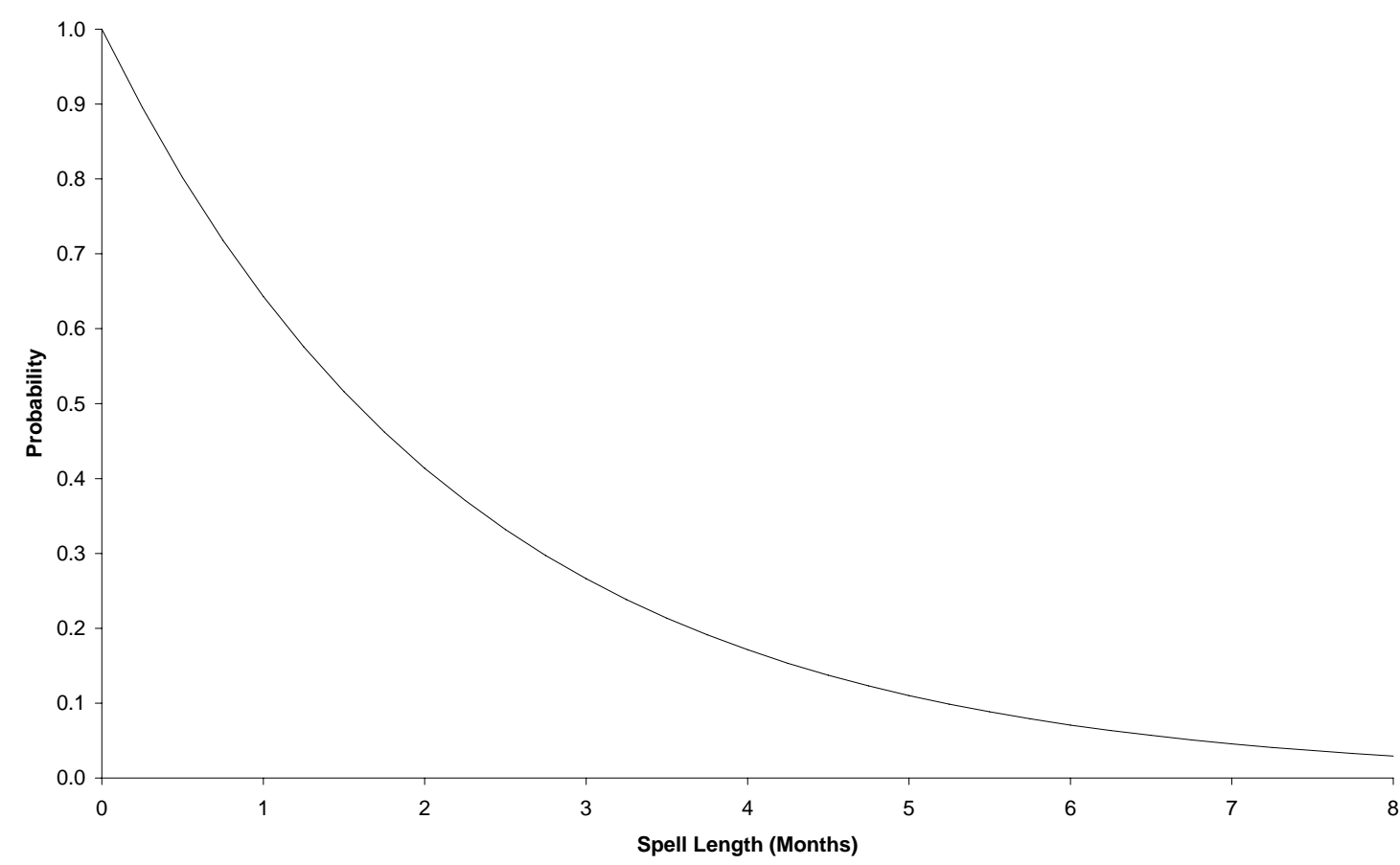


Figure 5: Weibull Hazard Function

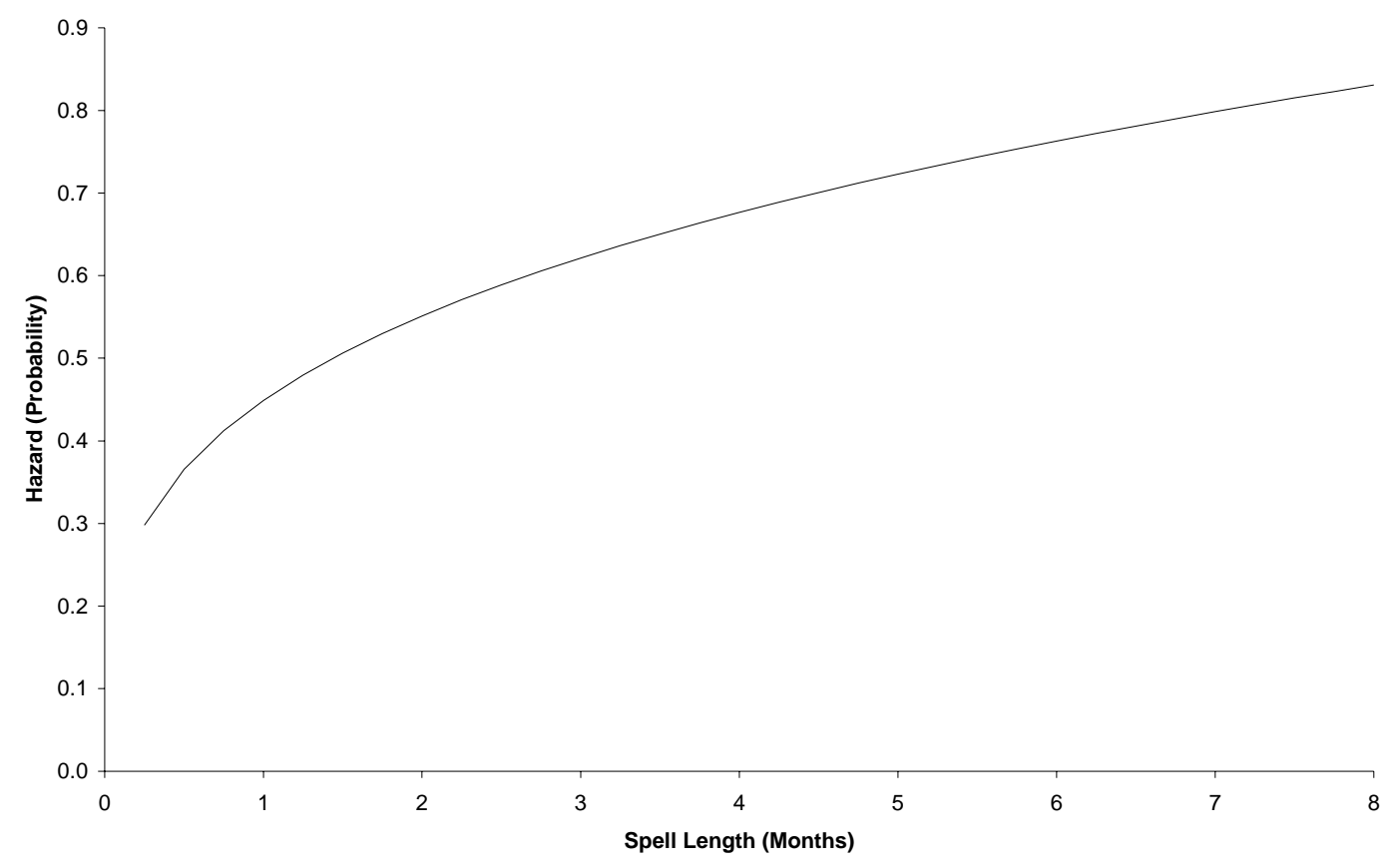

Figure 6: Weibull Cumulative Hazard Function

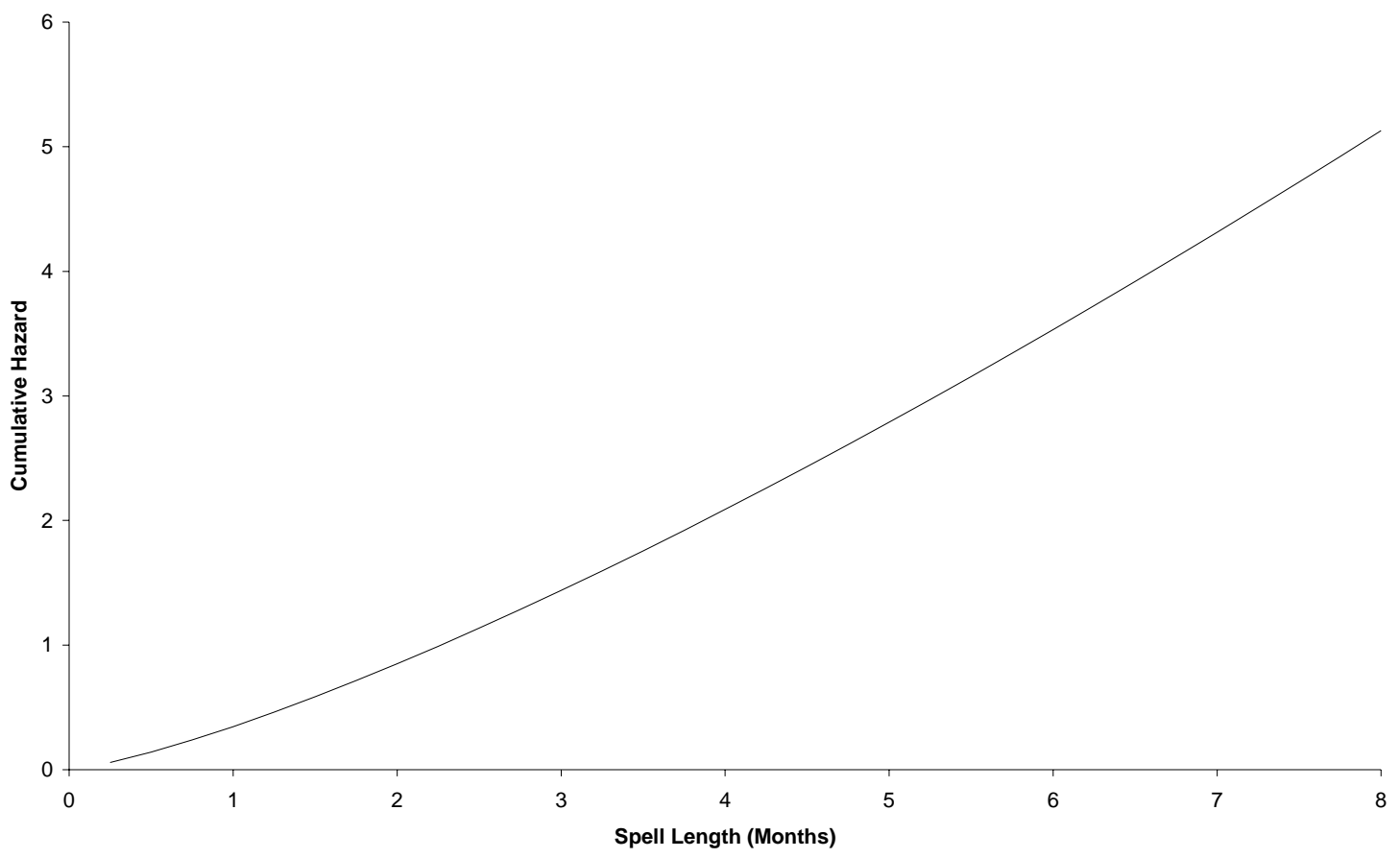




\section{References}

Bank of Canada Website, http://www.bankofcanada.ca/en/

Dib, A. (2006), "Nominal Rigidities and Monetary Policy in Canada", Journal of Macroeconomics, 28, 303-325.

Gerlach, S. and F. Smets (2000), "MCIs and Monetary Policy", European Economic Review, 44, 1677-1700.

Giles, D. E. (2006), "Survival of the Hippest: Life at the Top of the Hot 100", Applied Economics, in press.

Greene, W. H. (2002), LIMDEP Version 8.0, Econometric Software Inc., Plainview NY.

Greene, W. H. (2003), Econometric Analysis, $5^{\text {th }}$. ed., Prentice-Hall, Upper Saddle River, NJ.

Greenwood, M. (1926), The Natural Duration of Cancer, Reports on Public Health and Medical Subjects, His Majesty's Stationary Office, London.

Hüfner, F. (2004), Foreign Exchange Intervention as a Monetary Policy Instrument - Evidence for Inflation Targeting Countries, Heidelberg, Physica.

Jonas, J. and F. S. Mishkin (2005), "Inflation Targeting in Transition Economies: Experience and Prospects", in B. S. Bernanke and M. Woodford (eds.), The Inflation-Targeting Debate, NBERUniversity of Chicago Press, Chicago.

Katz, L. F. (1986), "Layoffs, Recall and the Duration of Unemployment.” Working Paper, Department of Economics, University of California, Berkeley.

Kennan, J. (1985), "The Duration of Contract Strikes in U.S. Manufacturing." Journal of Econometrics, 28, 5-28.

Kiefer, N. M. (1988), "Economic Duration Data and Hazard Functions." Journal of Economic Literature, 26, 646-679. 
Lancaster, T. (1990), The Econometric Analysis of Transition Data, Cambridge University Press, Cambridge.

Leung, M. K., Rigby, D. and T. Young (2003), “Entry of Foreign Banks in the People's Republic of China: A Survival Analysis", Applied Economics, 35, 21-31.

Li, K. (1999), "Bayesian Analysis of Duration Models: An Application to Chapter 11 Bankruptcy." Economics Letters, 63, 305-312.

Macklem, T. (2001), A New Measure of Core Inflation”, Bank of Canada Review, Autumn.

Quantitative Micro Software (2004), EViews 5 User's Guide, Quantitative Micro Software, Irvine CA.

Setzer, R. (2004), “The Political Economy of Exchange Rate Regime Duration: A Survival Analysis", mimeo., University of Hohenheim, Museumsflugel, Germany.

Wälti, S. (2005), “The Duration of Fixed Exchanged Rate Regimes", mimeo., Department of Economics, Trinity College Dublin.

Xie, Y. (2006), "Duration Analysis of U.S. Patent Approvals", M.A. Extended Essay, Department of Economics, University of Victoria.

Yu, Y. Y. (2005), "Modelling Exchange Rate Regime Durations", M.A. Extended Essay, Department of Economics, University of Victoria. 


\section{Footnotes}

* We are grateful to Graham Voss for helpful comments on an earlier version of this work.

1. Details about inflation targeting in transition countries are given by Jonas and Mishkin (2005).

2. Once the band is breached, the Bank will take some actions to pull the inflation back to the band.

3. For more details, see http://www.bankofcanada.ca/en/

4. Ties occur when two or more observations have the same duration.

5. The sample mean is 2.3 months, with a maximum spell-length of 8 months.

6. See Greene (2003, p.797) for the expression of the conditional mean for the Weibull and other models.

7. These authors estimated policy rules, and did not consider the duration of interest rate spells per se. 